\title{
Etnography of high school women: gender pedagogy approach to intimacy
}

\begin{abstract}
This paper discusses an approach to the narratives of young high school women between 16 and 21years old. In this work through ethnography technique we recover the beliefs, expectations, myths, and stories of gender violence that go through the students and offers personal development tools. The recovery of these life stories show us a panorama of these women's visions of life, of what they think of intimacy; their worries, and future expectations. We research how the stories of adolescents contribute to the construction of their identity between peers and among family relationships; the meaning they give to their lives and the family role in all this. This paper shows the value to generate personal spaces from the experience lived by women and the events that have marked them; based on these markers, a teacher's methodology in the classroom has to be modified, because academic spaces also creates a violent environment instead of creating alternative, diverse and encouraging spaces. This work allowed us to explore the complexities and nuances of life as adolescent women; highlighting the ways in which women develop and maintain their most significant affective bonds, as well as the challenges they face in their daily dynamics. It also allowed us to know their new ways of appropriating the classroom work dynamics. Young women are tired of the segregation that perpetrated in their families, participating in domestic work as a way of life; they want the type of life that has been confined to men. What they have narrated about their desires and dreams is quoted; feelings of sadness and emptiness are the constant in their life. We challenge teachers to use these practices or methodologies to gather invaluable information about who we are training; so we can make visible the acts of resistance that many of the female young students go through in their daily dynamics visible to all.
\end{abstract}

Keywords: etnography, feminism, family, narratives, violence
Volume 3 Issue 4 - 2019

\section{Tanya Elizabeth Méndez Luévano, Orlando Reynoso Orozco \\ Center of Social Sciences and Humanities, Guadalajara University, Mexico}

Correspondence: Orlando Reynoso Orozco, Associate Professor Periférico Norte $N^{\circ} 799$ Núcleo Universitario, De Los Belenes, 45100 Zapopan, Jal, Mexico, Tel 5233 33।3849356, Email orlando.reynoso@academicos.udg.mx

Received: July II, 2019 | Published: July 22, 2019

\section{Introduction}

Become aware of how is our world going? Is try to understand how the educational dimension has to be involved and deal with the indeterminable realities that we live; the problems that arise in daily life; and the demands of the community that goes to the classroom? The recovery of these narratives will allow us to know and recreate the spaces and cultural dynamics that challenge this young woman; since they show us a panorama of their vision of life, of what they think of intimacy, of what worries them and what are important for them in the future. The stories and narrations of people are invaluable historical resources that open the possibility for an understanding from the outside, of aspects that give meaning to the lives of people and that rarely find spaces to show it. Therefore, to investigate how the stories of adolescents contribute to the construction as women in the context of their family relationships and what meaning they give to their lives and what role school plays in all this, is part of what was collected in this paper.

The usefulness of these exercises in the pedagogical work within the classrooms, is not only to allow people to speak from their experience and understand or transform their environment, but also to recover the context of violent and oppressive gender policies immersed in the structures narratives, in the connotations and constructions of the daily life of school spaces. This piece of life can generate an empathic change in the classroom, first, as a resistance to the naturalization of women's bodies; second, the observation of the dialogical reflection that can be generated through experiences of the students and their professors. Things happen outside the classroom; violence against women is so naturalized, the students express their fear by walk from their home to school; pass through buildings or parks where they have been attacked or harassed, or in the same academic spaces, were teachers siege them. This document presents an emerging field of practice with young female high school students. This project uses narrative practices from an auto ethnographic process to awaken and reflect on their life conditions and relationships, inside and outside their most significant spaces as an individual, with their families and communities. The narrative practices used as a methodological technique in the work with young women, allowed knowing the constructions that make of their historical, social and individual evolution and the effects in their daily lives. The narrative practices have been used in different approaches; it is a method that aims to give voice to those stories that dominate the effects of the constant relationships between people and their most significant dynamics, where people are the only experts. Words give meaning to lived realities, which could have different meanings. ${ }^{1}$

In the narrative paradigm the person is an active protagonist (personal agency) of his life, who can rewrite and co-create with other people a new history of his identity. In this same paradigm, the position of the observer is recognized in the stories because they are co-produced and established as conditions to return the subject's authorship; defining the position of the observer as collaborative, not that of the expert who tells the client what to do, based on speeches standardizing and/or hegemonic to respond to each discipline. ${ }^{2}$ The autobiographical-narrative method, as part of the life stories, has 
as objective to show the subjective testimony of a person and the valuations about its own existence. ${ }^{3}$ With these stories, the aim is to bring the reader closer to the world of the protagonists and the social and cultural context that surrounds them. The history life is a research strategy, aimed at generating alternative versions of social history, based on the reconstruction of personal experiences. It constitutes a resource of first order for the study of human events, because it facilitates knowledge about the relationship of subjectivity with social institutions, their imaginaries and symbolic representation. ${ }^{2}$ The history of life allows everyday life events to be translated into words, gestures, symbols, anecdotes, stories; constitutes an expression of the permanent interaction between personal history and social history. As an instrument for research work, the history of life has been used by different social disciplines. In anthropology it was used in a special way by Oscar Lewis in his studies about the culture of poverty in Mexico, Puerto Rico and New York. ${ }^{4}$

In the last two decades of the last century, in some sociological approaches, autobiographical method's has been recognized and developed as an alternative to deepen into the study of subjects, such as intimacy of individuals, social mobility, the life cycle, social movements, the image of themselves, among others. ${ }^{5-7}$ Both sociology and history have turned to the history of life narratives to register oral testimonies through which relevant problems are characterized and new explanations are sought for human events. ${ }^{8,9}$ The narrative practices employed in this work allow us to change the perception about women imagen, who fundamentally have suffered violence. The narrative practice with young women as a methodological technique also allowed us to know the constructions that make of its historical, social and individual evolution and its effects. ${ }^{1,11}$ The narrative practices have been used in various psychological approaches and in social intervention, as a way of rejecting the search for diagnoses or statistics. In terms of source of information, we emphasize the need to address a feminist perspective in educational spaces exclusive for women, such as the Center for Industrial Technological Baccalaureate and Services. This approach is essential for a country such as Mexico and, in particular Jalisco state, where the increase in femicide and violence against women is a reality and a phenomenon little studied from the classroom, as a preventive factor for risk behaviors.

\section{Methodology}

The teaching experience has shown us how the implementation of new qualitative resources allow us to know the intimate sphere between interlocutors; which can be key strategy so that students could be able to identify their historical sense and generational identification product of the approach to autobiographical stories. Our qualitative research comes from the personal sphere; it is the recovery of the autobiographical story, which in turn becomes powerful in the relationship with the other; as a reader of a discourse or story that reinvents an updated story in the mind of the author. This autobiographical narrative is a text of interpretative nature, generated by a speaker who elaborates his past and gives meaning to it through the operation of memory. This process does not reconstruct episodes according to how they were lived at the time, or try to recreates the journey of a life, but generates a new product, of a textual nature, whose meaning is configured according to the time and circumstances in which it occurs. ${ }^{12}$ Here, narrative proposal that has been used in this process with students women; the idea of the external witnesses (the teacher), used in the therapeutic work ambient or with groups sessions, was also implemented in these study. The function of the external witness is to act as the invited listener to the therapeutic conversation, in individual, collective or group processes, among others; invited to listen and know the favorite stories and the identity statements of the person who consults. These external witnesses can be part of the social circle of the person or can be invited by other people to these support networks, in which case they can be professionals, friends or other. ${ }^{1}$ The implementation of this practice make possible that students to become visible from the resources they have been implementing to forge goals, continue with their lives regardless of adverse situations and explore such coincidences in the more valued aspects in their lives. To start the autobiographical process, documentary was first projected in the classroom to sensitize and converge about empathic and diversity of lives. ${ }^{13}$ these exercise make possible to face critically and reflexively the relationship with themselves, their personal history and their family relationships and their social environment. Then, a series of questions (see questionnaire) were provided so they could be used as a guide for the ethnography process, they were answered anonymously.

\section{Results}

Narratives of young women between 16 and 21years old $(n=120)$ were analyzed. The way in which we categorized this work was from the stories that the same girls were describing in one of the autoethnographic exercises. Here we will present the results of our analysis and the discourses that prevail. Altogether we gathered one hundred and twenty girls who wanted to participate in this work as the end of the course. The work consisted of the elaboration of their life stories, whose narrations give account of the closest domains of the students as, for example, the family, their immediate dynamics, and their relationships, the most significant aspects for them, the couples, and the bodies, which are exposed in the following sections.

\section{Family relationships}

This analysis begins with the family domain because it is the closest and most intimate of the contexts; where beliefs, myths and expectations are recreated. The narratives that students express about the links with their parents seems to us a very important aspect; since it can be a source of strengthening the networks that favor the formation of positive lifestyles that contribute to their personal growth, and to take decisions. Everything that they narrate forces us to rethink the function that the family institution should fulfill, rather than as normative containment, as a preventive and positive accompaniment to young people, and what happens when this support is not adequately perceived:

a) My life has not been easy because in my family I do not have an example to follow (18years)

b) My mom does not agree with my career, she always reproached me for taking this profession (22years).

c) In my family I always had many conflicts with my sister; we are always fighting at all times (21years).

d) I have many problems at home, since my sister the youngest, grabs all my things (22years).

e) It hurts me not to have my father, who is not with me, I'm used to just being with my mom and from time to time I see my dad (19years).

f) My family is something dysfunctional and now that we all 
live together and there is no space; we are 5 brothers, and two of them already have children's, plus my parents. My brothers worry me because they do not like to study and they do not want to go to school (18years old).

g) My mom cannot see my sister well because my sister is gay (18years old).

h) When I was little in my family there were many problems my dad and my mom fought a lot, sometimes they fight and hurt each other (17years old).

i) Currently studying high school I put a little laziness because I got tired of the demands of my family. I love all my family equally, but my grandparents are a fundamental part of my life and what I am. I do not know what would happen to me without them (17years old).

j) In my family there are problems with my brother that have a very strong character and when there is a problem with him there is tension and everything separates (16years).

k) My paternal grandfather died two years ago, he was a very good person with us, my grandmother was always a gossip person who always meddled in things that did not matter to him, saying that my childhood had happy moments and others not, it is for her fault, because with my sister and me it was always a different person, since the treatment she gave to my cousins was always very different. My grandmother always treats to my mother in a very bad way, degrading her. She put my father against her, so my mother was the "bitch" without more or less. My aunts sisters of my dad were just like my grandmother. My father has always worked outside the city. They ears that I have are the same as he has not been (18years).

\section{Family support}

In this section, the bond that is perceived as positive in some ways, creates moments that reassure them; since they have supported when something disturbs them, they understand that there is a close accompaniment that will contain them if something is not right at home or with other members of their immediate space, they can count on a parento marental figure, which is fundamental for them. This ability to feel close to the peer group is a practice that is transmitted culturally and from generation to generation, they are linking the development of empathic protection, but there is a great deal of education and satisfaction of the needs that were learned.

a) With my father I get along very well, he supports me in everything even though my mom has all the management of the house (22years).

b) I'm grateful with my mom for everything she has done for me. In my family I have always had many conflicts with my sister; we are always fighting at all times (18years).

c) Another of the things I love most is that my parents and my whole family continue together as they do right now (19years).

d) I consider my family to be very close to each other (17years).

e) My parents are together and happy for 19years or well those make us think (17years).

f) My life is my family, my friends, my brothers; they are the most important thing that I have, although they are not very attentive to me, they are my life and I owe them a lot (17years).

g) One of the most important things for me is my family (17years).

h) To be recognized for my mom I love the whole family, but the more is that my mom be proud of me and say "congratulations" "I knew you were able of this and more" (18years).

i) My family is important to me (18years).

j) My brothers and i have a different father; for me, my only family are my brothers, their children, and my mother (16years).

k) I love my little family we are perfectly imperfect (17years).

1) The relationship with my family is good; I always have the support of my parents and sisters (18years).

m) I would like to have the support of my mother to study performing arts since I don't have a father (17years).

n) It broke all the expectations that I had of her and I know that although I return nothing will never be the same again, even if it is my mom and it is hard to listen to, it does not deserve to have my dad and my brothers by her side (17years).

\section{Parents separation or divorce}

Numerous sociological and psychological studies reports that fragmented, absent or poor links between parents are a risk factor for young social problems (such as addictions, violence, alcoholism, early pregnancies, etc.). Faced with these analyzes, the positions we found in our study were that these young women were not always a factor related with school desertion or negatives changes in daily lives. Instead, some have develop and mature psychologically; and change their family dynamics or lifestyles. It seems that the girls had to assume and become accustomed to the decisions of their fathers or mothers, without judging, which also shows that the culture has changed in the beliefs of a marriage; even few of them have manifested that their parents talk about this, so it is interesting to find out what narratives they form about marriage or the couple.

The education that daughters continuously receives attenuate patriarchy; that is, the null couples support who tend to go away once they have separated, leaving women in a situation of vulnerability, with a precarious economy and inadequate vision of what maturity is in young women; situation that leaves them with high emotional stress, because they have to accept roles that are not relevant to their age and development. This situation of abandonment leaves them with stereotypes that demarcate their idea of women: as caregivers, support, among other things, they are segregated to domestication environment as an inherent part of being a woman. The experiences of separation can be perceived with difficulty and far from bringing them closer to having a healthier connection with their mothers leads them down paths that may not be the safest for them.

a) When I was 6years old my parents separated and I had to mature at an early age ... I lived twice the separation of my parents (17years).

b) Turnaround my life in the middle of third year of junior high: change of house, separation from my parents (18years). 
c) The biggest disappointment was at 3years old when I knew that my parents were going to be separated because of my father's infidelity; since then I become a bit cold and to this day I think that is what has marked my life the most. My parents were together again and since the arrival of my sister all change in their relationship (16years).

d) My parents have been separated for 4years, I have two halfbrothers, I do not live with them or my father (16years).

e) Since my parents separated my life was a bit unstable. My mother got another couple and her attention was mostly for him (I hated him, I hate him) now they are not together anymore (thanks God) (17years).

f) Recently my parents divorced and I'm living with my dad and only on weekends I see my mom, which I do not like because I need both; but I guess you cannot do anything about it because I cannot ask my Mom to come back (17years).

g) My mom divorced my dad (physical violence) and he move out us from our house after 3 months of being there alone (16years).

h) My parents for some reason separated, my dad left leaving us alone to my brothers and my mother (my mother establish a relationship with my dad brother). Then they came back together and separated again. When they had been separated for three years, they divorced (17years).

i) My dad left us when i was eleven years old, that ended when I turned 16 and a man came back to follow him, calling him dad (17years).

j) I had to take care of my brother 3years younger, I been raised me with my grandparents (18years).

k) Since I was young I had home responsibilities like work and monetary responsibilities to help in the expenses of my house (16years)

1) My concern at this moment is my mom, because she cannot walk and I am the one who makes the breakfast and the food, I also take my sisters to school. My older sisters arrive later and they do the laundry. I also need to learn to drive because there are times when one of my parents gets sick and we have to talk to an uncle to take them to the medical services and apart from that I am the one in the house all day (19years).

m) I had to get absent from school a lot to take care of my dad (kidney surgery) since my mom and sister had to go to work and that was the reason why they kept me (18years).

n) I always take care of my younger sister, especially since 4th grade because; my mom had to start working because my father's salary was not enough to keep us 4 and his alcohol problems. When i was 8-9years old, I have to take care of my 6-year-old sister, I fed her, do homework, before going to elementary school, I had to make lunch for my dad. I started working at 13 or 14years (16years).

\section{Family redesign}

One way to know how feminism can help in the formation of young women, is to know the beliefs that still prevail about their role in the world, to change the systems of power is to contribute in the development of the self-image; the resources they have and how to get ahead if they have made decisions that do not favor them. Understand that their lives have opened in a different way than their mothers. To evolve cognitively and make it easier for them to return to their lives if they become pregnant. The dominant discourse has changed. In many contexts sexism is not socially accepted anymore, so daughter life redesign is what they should worry about; that is why it is essential to provide support and emotional bond that allows them to resume and restructure their lives as she decides, outside of stigmas or discourses that limit them and leave them exposed.

a) When my sister got pregnant, my father did not take it so badly, but my mother did; she told my sister that she will look for a place to live. It made me very sad because I did not want her to leave, it only lasted a while that she went to live with his partner and his son; then his partner left her, sometimes he came to visit my nephew, when he left every time the little boy cried because he wanted to go with him; a few months later he stopped going (17years).

b) Conflict relationships between brothers

c) In the narratives that dominate the stories of young women, meanings associated with intergenerational violence stand out. That is to say, the patterns of violence are repeated in stories with the brothers and sisters, in the same way than fathers and mothers lived it of their own; the above agrees with the fact that have been a victim of violence in childhood may increase the risk of repeating such stories at later ages or be enrolled in the same family dynamics.

d) My brothers fight each other in my house and my younger brother was put in jail, I had a lot of appreciation for him, however something changed (he got into drugs) among my three brothers he is the one I least want. I have an older sister; I love her too much, after my mom she is my example to follow, although from a young age I felt that she was jealous of me and did not love me (16years).

e) With my sister I never got along well she treated me badly and excluded me, which I feel was "because I took her place" but lately our relationship has improved (17years).

\section{Social networks}

When the fathers are involved in the care of their children, it is likely that the stigma that falls on the mother of being the sole caregiver responsible for both the off spring, will be lived and perceived in another way that maternal function. There are studies that show that when mothers feel emotionally and functionally supported, discourses and family dynamics are more functional, which is also perceived by the children.

a) My godmother is to me is like my second mom, she was always taking care of me and is someone very special to me. Who is important to me? My parents, my brother, my grandpa and my godmother. If I'm with them I do not lack anything (17years).

b) My mother is the one who supports me emotionally and financially, for that reason I want to finish studying with a good school average (16years). 
c) My family has always supported me, has always been attentive to me, I thank my brother very much because I not only see him as my brother but also as my second father and he is motivation and example (16years).

d) My parents are supporting me to finish high school but in college they will not do it (18years).

e) One of the hardest times of my life was when my sister started with depression before divorce, she starts cutting with knives, took a pills, she require mental health hospitalization and was very difficult for me because of my young age (16years).

f) There was one event in particular that completely destroyed me, it was to arrive at home and seeing that your mother is not there, that she left the house and only leave you a letter in which she hypocritically tells you that she loves you and that you were not a of the reasons for the abandon. But later you find the letter that she leave to your dad and notice that you were one of the reasons. And later find out that he left with someone else (17years).

\section{Discussion}

The auto ethnographic narratives that the students shared with us brought us closer to the difficulties and tensions that they face every day in the construction of their relationships, the perception of themselves and the expectations that are generated throughout their life with others eyes people with which they are related or that have been significant to them. It is also important to point out the imminent need that students have to know new ways of approaching their problems and the new aspects that exist as women in a world that should respond to the diversification of spaces for everyone. Fundamentally, we believe that the students need to feel that the school is a space of support, a place that gives and intensifies their motivations and life expectancies. Having that privilege of being students makes it possible for them to resist the discourses that dominate them. From the academic institutions' perspective, pressure should be exerted on political and governmental institutions to protect and safeguard the women's bodies. These commitments are necessary for eradicating discrimination, reification, segmentation and feminization of girls and women. The pressure from these experiences is intense, demonstrates the neglectful environments in which young women are and exists. Social and emotional support is only the beginning. Institutional processes need to be in place to recognize and transform toxic environments into accepting safe places for young women to study and grow.

\section{Acknowledgments}

None.

\section{Conflicts of interest}

The author declares there are no conflicts of interest.

\section{Funding}

None.

\section{References}

1. White M. Definitional ceremony and outsider-witness responses. 2002.

2. Gergen K, Warhus L. Therapy as a social construction dimensions, deliberations, and divergences. Venezuelan journal of community clinical psychology. 2003;3(3):13-45.

3. Pujadas JJ. The biographical method: the use of life stories in social sciences. Madrid: Center for sociological research; 1992. p. 1-17.

4. Lewis O. Life. Mexico: Universidad Autónoma Metropolitana Unidad; 1964. p. 8 .

5. Balan J. The stories of life in Social Sciences: Theory and Practice. Buenos Aires: New Vision; 1974. 217 p.

6. Bertaux D. The life stories in social analysis. Mexico: Mora-UAM Institute; 1989. p. 136-148.

7. Córdova V. Life stories An alternative methodology for Social Sciences. Caracas: Ed. Tropycos 1; 1990. 84 p.

8. Archila M. Culture and worker identity. Bogotá: CINEP; 1991. 193 p.

9. Molano A. The years of the Tropel. Bogotá: CINEP/CEREC; 1990. p. 358-361.

10. Bruner E. Experience and Its Expressions. In: Turner VW, Bruner EM, editors. The Anthropology of Experience. 1986. 199 p.

11. White M, Epson D. Narrative means for therapeutic purposes. Barcelona: Paidós; 1993. 110 p.

12. Piña C. Time and memory On the artifices of the autobiographical story. Propositions; 1999. p. $1-5$.

13. Arthus Bertrand Y. Human the Movie. 2015. 1: p. 25. 